University of Nebraska - Lincoln

DigitalCommons@University of Nebraska - Lincoln

Effect of various photoperiods on testicular weight, weekly sperm output and plasma levels of $\mathrm{LH}$ and testosterone over the reproductive season in male turkeys

\author{
Jérôme Noirault \\ INRA \\ Jean-Pierre Brillard \\ United States Department of Agriculture, brillard@tours.inra.fr \\ Murray R. Bakst \\ USDA
}

Follow this and additional works at: https://digitalcommons.unl.edu/usdaarsfacpub

Part of the Agricultural Science Commons

Noirault, Jérôme; Brillard, Jean-Pierre; and Bakst, Murray R., "Effect of various photoperiods on testicular weight, weekly sperm output and plasma levels of $\mathrm{LH}$ and testosterone over the reproductive season in male turkeys" (2006). Publications from USDA-ARS / UNL Faculty. 673.

https://digitalcommons.unl.edu/usdaarsfacpub/673

This Article is brought to you for free and open access by the U.S. Department of Agriculture: Agricultural Research Service, Lincoln, Nebraska at DigitalCommons@University of Nebraska - Lincoln. It has been accepted for inclusion in Publications from USDA-ARS / UNL Faculty by an authorized administrator of DigitalCommons@University of Nebraska - Lincoln. 


\title{
Effect of various photoperiods on testicular weight, weekly sperm output and plasma levels of LH and testosterone over the reproductive season in male turkeys
}

\author{
Jérôme Noirault $^{\mathrm{a}}$, Jean-Pierre Brillard ${ }^{\mathrm{a}, *}$, Murray R. Bakst ${ }^{\mathrm{b}}$ \\ ${ }^{\mathrm{a}}$ INRA, Station de Recherches Avicoles, Centre de Tours, 37380 Nouzilly, France \\ ${ }^{\mathrm{b}}$ Biotechnology and Germplasm Laboratory, ARS, USDA, Beltsville, MD 20705, USA
}

Received 24 May 2004; accepted 11 November 2005

\begin{abstract}
The effects of duration and variation in photoperiod on testis weight, testicular sperm production, semen output, and hormone status over the reproductive season in male turkeys were investigated. In Experiment 1, four groups of males raised from 17 to 23 wk of age under a constant short photoperiod were subjected to a constant short (Group 1: 7L:17D; Group 2: 10.5L:13.5D), constant long (Group 3: 14L:10D) or progressively increasing photoperiod (Group 4: 7L:17D to 14L:10D) up to 60 wk of age. In Experiment 2, four groups of males first raised as in Experiment 1 up to $23 \mathrm{wk}$ of age were placed under a constant short (Group 5: 10.5L:13.5D), constant long (Group 6: 14L:10D), or night-interrupted photoperiod (Group 7: 6L:2.5D:1L:14.5D, referred to as subjective 9.5L:14.5D; Group 8: 6L:3.5D:1L:13.5D), referred to as subjective 10.5L:13.5D) up to 60 wk of age. Males in Groups 2-4 had similar reproductive characteristics, whereas sexual maturity was delayed from 29 to 49 wk in males from Group 1 . In Experiment 2, males in Groups 5 and 8 had similar reproductive characteristics, whereas sexual maturity was delayed in males in Group 7 in a manner similar to that observed in Group 1. In both experiments, plasma LH and testosterone concentrations were poor indicators of testis development and semen production, irrespective of age and photoperiod. We conclude that a moderately short photoperiod such as 10.5L:13.5D or subjective 10.5L:13.5D may stimulate reproductive characteristics of male turkeys in a manner comparable to constant long or increasing photoperiods. We inferred the existence of a threshold of photosensitivity in male turkeys for photoperiods longer than $9.5 \mathrm{~L}: 14.5 \mathrm{D}$, but shorter than or equal to $10.5 \mathrm{~L}: 13.5 \mathrm{D}$.
\end{abstract}

(C) 2006 Elsevier Inc. All rights reserved.

Keywords: Photoperiod; Spermatogenesis; LH; Testosterone; Turkey

\section{Introduction}

Variations in photoperiod are used in the commercial poultry industry to maximize growth and reproductive performance. Photostimulation is accompanied by increased LH and FSH secretion from the anterior

\footnotetext{
* Corresponding author. INRA, Station de Recherches Avicoles, 37380 Nouzilly, France. Tel.: +33 2474276 45;

fax: +33247427778.

E-mail address: brillard@tours.inra.fr (J.-P. Brillard).
}

pituitary gland which, in turn, initiates testicular development and Leydig cell proliferation. Testicular steroids, mainly testosterone, act with FSH to regulate spermatogenesis and also exert negative feedback on the secretion of the gonadotrophins [1]. In addition, plasma LH concentrations increase during the phase of rapid growth of the testes in males subjected to photostimulatory daylengths both in the fowl and turkey [2-5]. In males from previously named species, LH and testosterone are discharged in pulsatile patterns during both the photophase and the scotophase of the nycthemere. Moreover, it appears that in mature male 
turkeys, a pulsatile pattern of testosterone is maintained regardless of its baseline concentration, whereas the pulsatile pattern of LH is maintained only if associated with low plasma concentrations of both $\mathrm{LH}$ and testosterone [6,7]. Turkey males in semen production exposed to continuous or intermittent light regimes had minor differences in patterns of $\mathrm{LH}$ and testosterone secretion $[7,8]$. Immature male turkeys exposed first to a short (6L:18D) and then to a long photoperiod (16L:8D) had marked increases in plasma concentrations of both LH and testosterone during the first 4 wk following photostimulation [9]; this was followed by an increase in testis weight but not in semen output. A nonreversible regression of the testes followed the onset of sexual maturity in turkey males exposed to long photoperiods from the first weeks after hatching [10]. Alternatively, short photoperiods (7L:17D) delayed the onset of testicular development and semen production, but maintained it longer into the season $[10,11]$.

George [12] suggested that elucidation of the relationships between light management and semen production relative to maximum sustained fertility and hatchability would be of substantial interest to the poultry industry. Other than work by Bacon et al. [7], there has been little fundamental research with commercial breeder turkeys addressing the role of photoperiod on the endocrine control of semen production. The objectives of the present study were to assess the impact of various photoperiods on testis development, semen output, and hormonal (LH, testosterone) status in male turkeys over a reproductive season.

\section{Materials and methods}

\subsection{Animal husbandry}

\subsubsection{Experiment 1}

A total of 105 immature male turkeys (BUT 6 medium, British United Turkeys, Chester, UK) were initially subjected to a progressively decreasing photoperiod $(-1 \mathrm{~h} / \mathrm{wk})$ from 11 up to $17 \mathrm{wk}$ of age and then maintained at a 7L:17D photoperiod for $6 \mathrm{wk}$. At $23 \mathrm{wk}$ of age, males were randomly divided into four groups ( $n=30$ in each group), placed in environmentally controlled chambers at $21 \pm 4{ }^{\circ} \mathrm{C}$, and exposed to one of the following photoperiods: 7L:17D (Group 1), 10.5L:13.5D (Group 2), 14L:10D (Group 3), and from 7L:17D progressively increasing in light to $14 \mathrm{~L}: 10 \mathrm{D}$ (+1 h/wk from 23 to 29 wk of age, Group 4). Light in all photoperiods was provided by incandescent bulbs adjusted to 25 lux at the height of males' heads. Feed and water were provided throughout the experiment as recommended in BUT guidelines.

\subsubsection{Experiment 2}

Immature male turkeys $(n=200)$ at first raised under the same conditions as in Experiment 1 were divided into four groups at $5 \mathrm{wk}$ of age ( $n=50 /$ group). Group 5 was kept under 7L:17D up to $23 \mathrm{wk}$ and then placed under 10.5L:13.5D up to 59 wk. Group 6 was subjected to a constant 14L:10D from 5 to $59 \mathrm{wk}$. Groups 7 and 8 experienced a progressively decreasing photoperiod from $14 \mathrm{~L}$ to $7 \mathrm{~L}(-1 \mathrm{~h} / \mathrm{wk})$ between 11 and $17 \mathrm{wk}$ of age and then either maintained under a constant night interrupted photoperiod of $6 \mathrm{~L}: 2.5 \mathrm{D}: 1 \mathrm{~L}: 14.5 \mathrm{D}$ up to 59 wk (referred to as a subjective $9.5 \mathrm{~L}: 14.5 \mathrm{D}$ photoperiod; Group 7) or a $6 \mathrm{~L}: 3.5 \mathrm{D}: 1 \mathrm{~L}: 13.5 \mathrm{D}$ photoperiod up to 59 wk (referred to as a subjective $10.5 \mathrm{~L}: 13.5 \mathrm{D}$ photoperiod, Group 8).

\subsection{Semen and blood collections}

Semen samples were obtained from each male by the same person using the abdominal massage technique [13]. All males (15/group) were trained to semen collection $2 \times / \mathrm{wk}$ from 25 to 29 wk of age. Semen (for semen evaluation) was then collected $5 \times /$ wk during weeks 30-33, 39-40, 45-46, 51-52, and 57-58. Male numbers per group decreased to 8-10 males/group by $60 \mathrm{wk}$ (Experiment 1) and $59 \mathrm{wk}$ (Experiment 2) after testicular samples were taken for analyses. Ejaculate volumes $(V)$ were estimated at the nearest microliter, and sperm concentration $(C)$ estimated with a photometer [14]. The total number of sperm/ejaculate $(T=C \times V)$ and the weekly sperm output (WSO) for each group was calculated. Sperm viability was estimated only in Experiment 1 from five randomly chosen males/group on the basis of five daily semen collections/male performed at $34,41,47,53$, and $59 \mathrm{wk}$ of age. The percentage of live/dead sperm in each ejaculate was assessed using the dual fluorescent probe Sybr14 + PI (Molecular Probes Inc., Eugene, OR, USA), as previously described $[14,15]$.

The same males were used for both semen evaluation and blood sampling. Blood samples were collected from the ulnar vein into heparinized syringes $(7.5 \mathrm{~mL} / \mathrm{male})$ and centrifuged $\left(1000 \times g\right.$ for $15 \mathrm{~min}$ at $\left.4{ }^{\circ} \mathrm{C}\right)$, and plasma was stored $\left(-20{ }^{\circ} \mathrm{C}\right)$ for radioimmunoassays (RIA). Blood samples were drawn once at $21 \mathrm{wk}$, then daily for 4 days at $23 \mathrm{wk}$, once at 24, 25, 26, 28, and 29 wk, respectively, and then fortnightly from 31 to $59 \mathrm{wk}$ of age. All sampling was performed between 10:00 and 11:00, with males always sampled in the same order. 


\subsection{Body and testes weights (BW and TW)}

In both experiments, five randomly selected males from each group were weighed and sacrificed (lethal dose of pentobarbital from Sanofi, Libourne, France) at $21,26,29,35,48$, and $60 \mathrm{wk}$ of age and their testes weighed to the nearest milligram.

\subsection{Hormone assays}

Plasma aliquots (50 $\mu \mathrm{L}$ each) for LH determination were assayed in triplicate [16]. This assay has been validated for turkey LH [17]. Because antibodies used for Experiments 1 and 2 came from different commercial origins, plasma samples used for hormone assays were treated independently. Immunoreactivity in serial dilutions of turkey plasma samples was parallel to the standard curve. Intra-assay variations for LH (four assays) were $2.8 \%$ (Experiment 1 ) and $4.3 \%$ (Experiment 2). Radioimmunoassays for testosterone were performed in duplicate $(100 \mu \mathrm{L}$ each) as previously described [18]. Intra-assay variations for testosterone (10 assays) were $3.9 \%$ (Experiment 1) and $11.3 \%$ (Experiment 2).

\subsection{Statistical analyses}

Experiments 1 and 2 were conducted over 2 different years and therefore treated separately for statistical analyses. Body weights, TW and WSO within each experiment were assessed using an ANOVA (factorial plan) to test the effects of age, photoperiod and their possible interaction. Within each experiment, results of plasma LH and testosterone were analyzed using a repeated-measures ANOVA and Fisher protected least significant difference (PLSD) test if appropriate. If there was a significant interaction between age and photoperiod, data were then reanalyzed to test the effects of photoperiod within each age. Correlation analysis (Pearson) was performed on selected variables (plasma LH, plasma testosterone, TW and WSO). Statview 5.0 for Windows software (SAS Institute, 2002) was used for all analyses and $P<0.05$ was regarded as significant.

\section{Results}

\subsection{Body weights, testis weights and weekly sperm output}

Body weight followed a similar pattern between groups at each age examined up to $35 \mathrm{wk}(P>0.05)$ but age and photoperiod along with their interaction influenced TW and WSO $(P<0.01)$. As a consequence, further comparisons between groups for each of these parameters were conducted at each age examined. At 26 wk, TW in Group 3 was greater than in other groups $(P<0.05)$ but at 29,35 and 48 wk TW were heavier in Groups 2, 3 and 4, respectively, than in Group $1(P<0.01)$. More specifically, at $29 \mathrm{wk}$, TW reached $57.1 \pm 4.2 \mathrm{~g}$ in Group 2, $59.4 \pm 4.4 \mathrm{~g}$ in Group 3 and $70.2 \pm 8.5 \mathrm{~g}$ in Group 4, compared to $21.0 \pm 9.8 \mathrm{~g}$ in Group $1(P<0.01)$. We also observed that among males from Group 1 euthanized at 26 and 29 wks, 1 and 2 out of 5 males, respectively, had TW similar to those observed in Group 3. Finally, at 60 wk of age, despite a tendency for heavier TW in Group 1 compared to other groups, statistical analyses revealed no inter-group differences for TW $(P<0.06)$.

Weekly sperm output followed patterns similar to those observed for TW (Table 1). Group 1 WSO was below $1 \times 10^{9}$ sperm from $31 \mathrm{wk}$ to 51 to $52 \mathrm{wk}$ of age. In contrast, WSO from Groups 2, 3, and 4 were 8.5 to $11.6 \times 10^{9}$ sperm. At $57-58 \mathrm{wk}$ of age, statistical differences were no longer observed between the four groups $(P>0.05)$. All males produced semen by $32 \mathrm{wk}$ in Groups 3 and 4, by 39 wk in Group 2 and by 57 wk in Group 1.

In Experiment 2, age, photoperiod and their interaction influenced TW and WSO $(P<0.05)$, justifying a reappraisal of analyses age by age. Males in Group 7 had smaller TW than in other groups at 26, 29 and 35 wk $(P<0.05$ at each age $)$ but these differences were no longer observed at 47 and $60 \mathrm{wk}$ $(P>0.05)$. As in Experiment 1, WSO followed patterns similar to TW (Table 1). For example in Group 7, males had smaller WSO than in any other groups up to 39-40 wk of age $(P<0.05)$, but these differences were no longer observed during the latter stages of the experiment $(P>0.05)$. Overall, all males in Group 6 produced ejaculates by 29 wk, Group 5 by 34 wk, Group 8 by 37 wk and Group 7 by 47 wk.

\subsection{Sperm viability (Experiment 1 only)}

Sperm viability (Table 2$)$ was higher $(P<0.01)$ at $34 \mathrm{wk}$ and $41 \mathrm{wk}(89 \%)$ than during the later stages of the experiment $(84,85$ and $84 \%$ at 47,53 and $59 \mathrm{wk}$ of age, respectively). Although turkeys under a 7L:17D photoperiod did not produce semen until $53 \mathrm{wk}$, the percentages of sperm viability in this group at 53 and 59 wk were not significantly different from other groups at the same age. 
Table 1

Effects of age and photoperiod on mean ( \pm S.D.) weekly sperm output (WSO; $\times 10^{9} \mathrm{sperm} / \mathrm{wk}$ ) in turkey males

\begin{tabular}{|c|c|c|c|c|c|}
\hline \multicolumn{6}{|c|}{ Experiment 1} \\
\hline \multirow[t]{2}{*}{ Age (wk) } & \multicolumn{4}{|c|}{$\mathrm{WSO} /$ treatment group } & \multirow[t]{2}{*}{ Probability } \\
\hline & Group 1 & Group 2 & Group3 & Group 4 & \\
\hline $30-31$ & $0.6 \pm 0.4^{\mathrm{a}}$ & $8.8 \pm 1.5^{\mathrm{b}}$ & $11.2 \pm 1.1^{\mathrm{b}}$ & $10.5 \pm 1.4^{\mathrm{b}}$ & $<0.01$ \\
\hline $32-33$ & $0.2 \pm 0.1^{\mathrm{a}}$ & $10.1 \pm 1.8^{\mathrm{b}}$ & $10.5 \pm 1.7^{\mathrm{b}}$ & $14.1 \pm 1.6^{\mathrm{b}}$ & $<0.01$ \\
\hline $39-40$ & $0^{\mathrm{a}}$ & $10.2 \pm 1.3^{\mathrm{b}}$ & $8.6 \pm 1.2^{\mathrm{b}}$ & $11.6 \pm 1.2^{\mathrm{b}}$ & $<0.01$ \\
\hline $45-46$ & $0^{\mathrm{a}}$ & $10.7 \pm 1.4^{\mathrm{b}}$ & $8.5 \pm 1.3^{b}$ & $8.5 \pm 1.1^{\mathrm{b}}$ & $<0.01$ \\
\hline $51-52$ & $1.5 \pm 0.8^{\mathrm{a}}$ & $8.5 \pm 1.6^{\mathrm{b}}$ & $7.1 \pm 1.5^{\mathrm{b}}$ & $5.7 \pm 1.1^{\mathrm{b}}$ & $<0.01$ \\
\hline $57-58$ & $3.8 \pm 1.1^{\mathrm{a}}$ & $6.0 \pm 1.5^{\mathrm{a}}$ & $6.8 \pm 1.5^{\mathrm{a}}$ & $5.6 \pm 1.1^{\mathrm{a}}$ & NS \\
\hline
\end{tabular}

Experiment 2

\begin{tabular}{|c|c|c|c|c|c|}
\hline Age (wk) & $\begin{array}{l}\text { WSO/treatr } \\
\text { Group } 5\end{array}$ & WSO/treatment group & Group 7 & Group 8 & Probability \\
\hline $30-31$ & $7.1 \pm 0.8^{\mathrm{a}}$ & $8.7 \pm 1.0^{\mathrm{a}}$ & $1.6 \pm 0.7^{b}$ & $3.0 \pm 0.8^{c}$ & $<0.05$ \\
\hline $32-33$ & $7.1 \pm 0.8^{\mathrm{a}}$ & $7.9 \pm 0.9^{\mathrm{a}}$ & $1.6 \pm 0.7^{b}$ & $3.9 \pm 0.8^{\mathrm{c}}$ & $<0.05$ \\
\hline $39-40$ & $7.8 \pm 0.8^{\mathrm{a}}$ & $8.0 \pm 0.9^{\mathrm{a}}$ & $1.7 \pm 0.7^{\mathrm{b}}$ & $4.5 \pm 0.7^{\mathrm{c}}$ & $<0.05$ \\
\hline $45-46$ & $9.2 \pm 0.5^{\mathrm{a}}$ & $8.9 \pm 0.9^{\mathrm{a}}$ & $6.0 \pm 1.2^{\mathrm{a}}$ & $8.1 \pm 0.7^{\mathrm{a}}$ & NS \\
\hline $51-52$ & $9.4 \pm 0.7^{\mathrm{a}}$ & $10.1 \pm 1.1^{\mathrm{a}}$ & $6.5 \pm 1.2^{\mathrm{a}}$ & $9.3 \pm 1.1^{\mathrm{a}}$ & NS \\
\hline $57-58$ & $8.8 \pm 0.6^{\mathrm{a}}$ & $8.0 \pm 0.9^{\mathrm{a}}$ & $6.0 \pm 1.3^{\mathrm{a}}$ & $9.7 \pm 0.7^{\mathrm{a}}$ & NS \\
\hline
\end{tabular}

All males collected 5×/wk. Experiment 1: Males were maintained under a 7L:17D photoperiod from 21 to 23 wk of age and then submitted to photoperiods of: 7L:17D (Group 1), 10.5L:13.5D (Group 2), 14L:10D (Group 3) or 7L/17D, progressively increasing (+1 h/wk) to 14L:10D (Group 4). Experiment 2: Males were maintained under a 7L:17D photoperiod from 21 to $23 \mathrm{wk}$ of age and then submitted to photoperiods of: 10.5L:13.5D (Group 5), 14L:10D (Group 6), 6L:2.5D:1L:14.5D (Group 7) or 6L:3.5D:1L:13.5D (Group 8), within each experiment, values at each age with different superscripts $(\mathrm{a}-\mathrm{c})$ differ $(P<0.05)$.

\subsection{Plasma LH and testosterone}

\subsubsection{Experiment 1}

No significant differences in plasma LH were detected between groups at $21 \mathrm{wk}$ of age (Fig. 1a and c). In Groups 1 and 2 (Fig. 1a) plasma LH increased gradually from 21 to $33 \mathrm{wk}$ and then remained stable up to the end of experiment (60 wk). In Groups 3 and 4, plasma LH increased abruptly within the first week (Group 3) or progressively during the first 4-6 wk (Group 4) of light stimulation (Fig. 1c). Plasma LH peaked at 23 wk in Group 3 and at 29 wk in Group 4, and then declined gradually before stabilizing up to $60 \mathrm{wk}$. Plasma LH remained comparable in all groups from 41 to $60 \mathrm{wk}$.

Notwithstanding erratic fluctuations, plasma testosterone slowly increased from 21 to 47 wk of age in Group 1 or from 21 to 31 wk of age in Group 2 (Fig. 1b). Plasma testosterone peaked between 23 wk and 26 wk of age in Group 3 and between 27 and 33 wk of age in Group 4 (Fig. 1d). After peaking, plasma testosterone remained comparable

Table 2

Mean $( \pm$ S.D.) viability of sperm $(\%)$ in ejaculates collected at various ages from turkey males subjected to different photoperiods

\begin{tabular}{|c|c|c|c|c|c|}
\hline \multirow[t]{2}{*}{ Treatment group } & \multicolumn{5}{|l|}{ Age (wk) } \\
\hline & 34 & 41 & 47 & 53 & 59 \\
\hline Group 1 & NA & NA & NA & $85.9+1.5$ & $86.7+3.5$ \\
\hline Group 2 & $90.9+3.6$ & $89.0+2.7$ & $84.1+2.0$ & $84.1+2.0$ & $82.6+3.2$ \\
\hline Group 3 & $89.1+4.7$ & $88.7+2.2$ & $83.6+2.6$ & $85.3+2.3$ & $85.1+1.7$ \\
\hline Group 4 & $92.0+3.2$ & $88.8+1.9$ & $83.6+0.9$ & $85.9+2.2$ & $83.8+1.0$ \\
\hline Age effect & $\mathrm{a}$ & b & $\mathrm{c}$ & $\mathrm{c}$ & $\mathrm{c}$ \\
\hline
\end{tabular}

Not applicable $(n<5)$. Values in columns with different letters $(\mathrm{a}-\mathrm{c})$ differ $(P<0.01)$. All males were maintained under a 7L:17D photoperiod from 21 to 23 wk of age and then submitted to photoperiods of: 7L:17D (Group 1), 10.5L:13.5D (Group 2), 14L:10D (Group 3) or 7L/17D, progressively increasing $(+1 \mathrm{~h} / \mathrm{wk})$ to $14 \mathrm{~L}: 10 \mathrm{D}$ (Group 4$)$. 

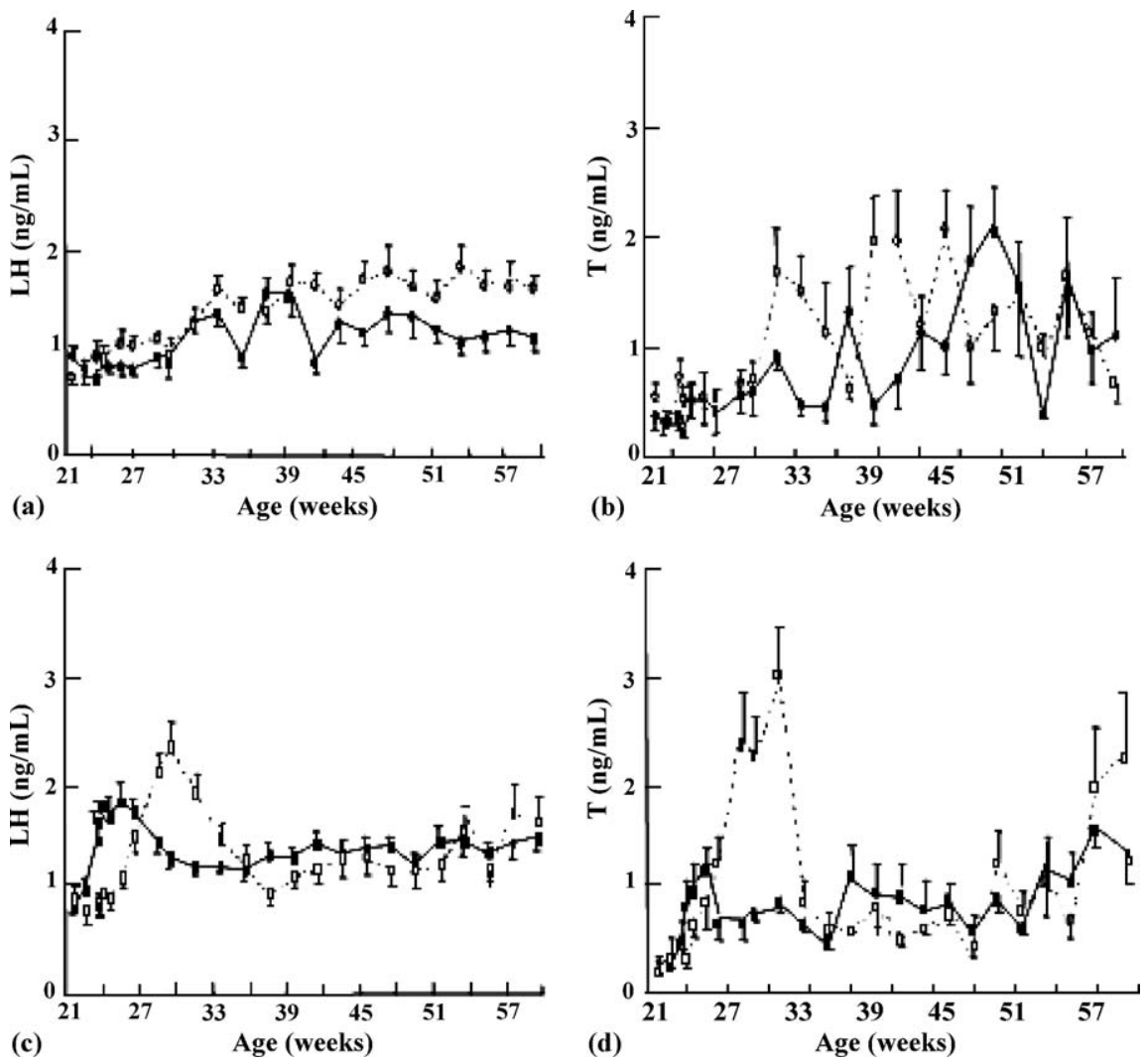

Fig. 1. Mean plasma LH (a and c) and testosterone (b and d) concentrations over a reproductive season in male turkeys under a constant or increasing photoperiod (Experiment 1). Males maintained under 7L:17D from 21 to $23 \mathrm{wk}$ of age and then subjected to a photoperiod of: 7L:17D (Group 1 ( O), a and b), 10.5L:13.5D (Group $2(\bigcirc-\bigcirc)$, a and b), 14L:10D (Group 3 ( $-\mathbf{\square})$, c and d) or 7L/17D, progressively increasing (+1 h/wk) to 14L:10D (Group $4(\square-\square)$ c and d). Each point represents the mean \pm S.E.M. of five individuals. Differences were observed between groups between 23 and $39 \mathrm{wk}$ of age for plasma $\mathrm{LH}$ and between 23 and $33 \mathrm{wk}$ of age for plasma testosterone $(P<0.05)$.

between groups through the end of the experiment $(P>0.05)$.

\subsubsection{Experiment 2}

There were effects of age and photoperiod $(P<$ 0.01) on plasma LH. By $21 \mathrm{wk}$, plasma LH in Group 5 was higher $(P<0.05)$ than in any other group (Fig. 2$)$. In Groups 5 and 6, plasma LH increased progressively up to 27 wk, in Group 7 up to 33 wk and in Group 8 up to $30 \mathrm{wk}$. Despite erratic variations, a general tendency favoring the stabilization of plasma LH level was apparent up to the end of the experiment (60 wk).

Effects of age and photoperiod were not observed in plasma testosterone in Experiment 2 despite significant differences between groups during weeks 21-28. During this period, plasma testosterone showed similar variation within Groups 5 and 6 and then within Groups 7 and 8 , before a general tendency for stabilization up to the end of the experiment.

\subsection{Interrelationships between TW, WSO, LH and testosterone (Experiment 1)}

In the absence of significant differences between groups for TW at $60 \mathrm{wk}$, WSO at $58 \mathrm{wk}$, plasma LH and testosterone at $59 \mathrm{wk}$, data from males sacrificed at $60 \mathrm{wk}$ of age were pooled for analysis of a possible correlation between these parameters (Table 3). The correlation was significant only between plasma LH and testosterone $(r=+0.37 ; P<0.05)$ but not between LH or testosterone and TW, nor between WSO and plasma LH, WSO and plasma testosterone or WSO and TW (Table 3). Overall, there was positive correlation $(P<0.01)$ between individual LH and testosterone plasma concentrations within each photoperiod, regardless of age (from 21 to $60 \mathrm{wk}$ ), with $r$ values of $0.47(n=217$, Group 1), $0.36(n=223$, Group 2), 0.25 ( $n=224$, Group 3), and $0.39(n=220$, Group 4). 

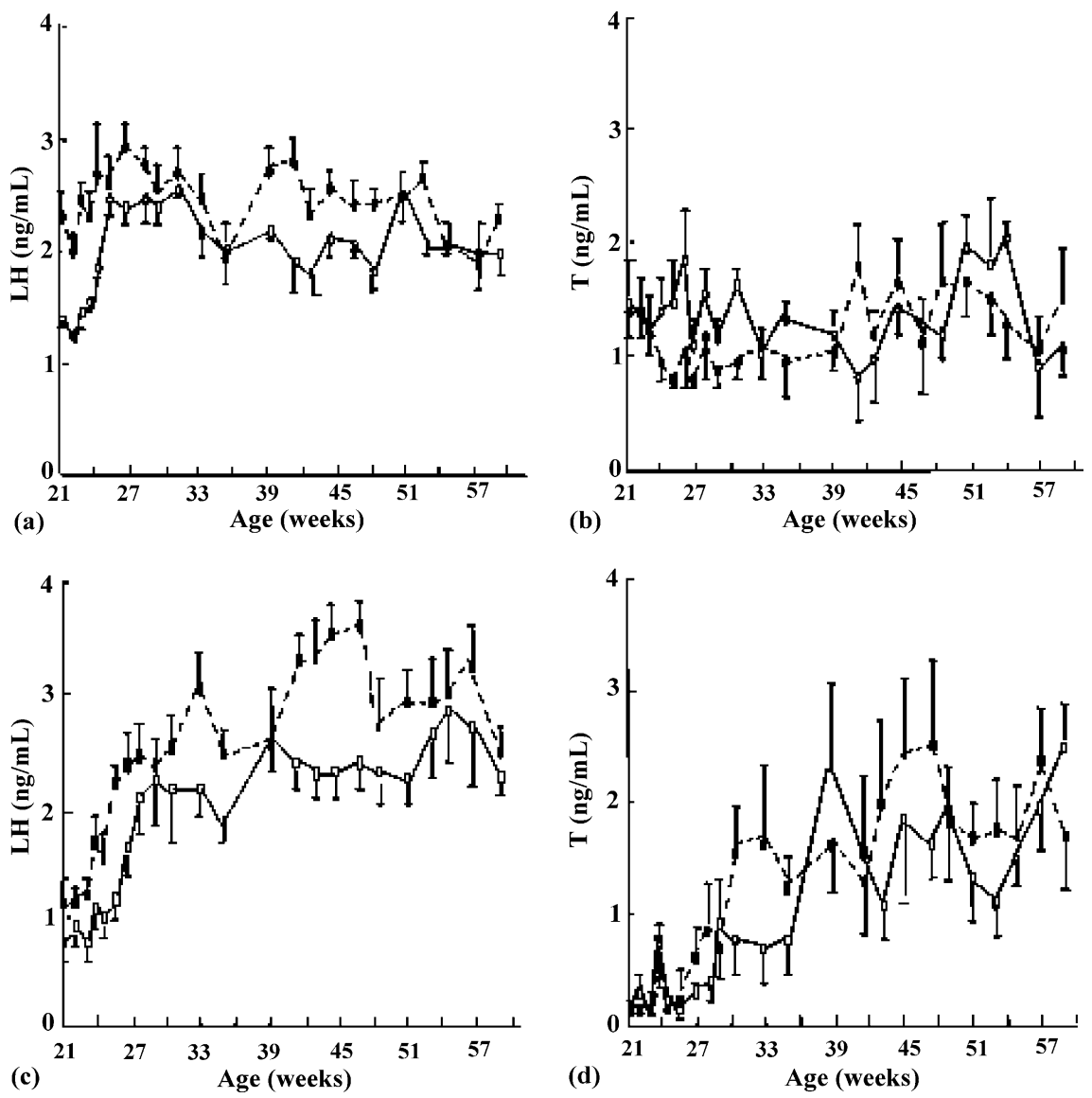

Fig. 2. Mean plasma LH ( $a$ and c) and testosterone ( $b$ and d) concentrations over a reproductive season in male turkeys under a constant or variable photoperiod (Experiment 2). Males maintained under 7L:17D from 21 to $23 \mathrm{wk}$ of age and then submitted to a photoperiod of: 10.5L:13.5D (Group 5 (-), a and b), 14L:10D (Group 6 (○-○), a and b), 6L:2.5D:1L:14.5D (Group 7 ( $\square-\square$ ), c and d) or 6L:3.5D:1L:13.5D (Group 8, $\square-\square$, c and d). Each point represents the mean \pm S.E.M. of 14-15 males from 21 to $47 \mathrm{wk}$ of age or 8-10 males up to the end of the experiment. Differences were observed between groups from 21 to $47 \mathrm{wk}$ of age for plasma $\mathrm{LH}$ and at 21 and $28 \mathrm{wk}$ of age for plasma testosterone $(P<0.05)$.

\section{Discussion}

The effects of different photoperiods on TW, WSO, and plasma $\mathrm{LH}$ and testosterone in breeder male turkeys over an entire reproductive season were examined. Previous studies using commercial breeder turkeys revealed a high degree of sensitivity to photoperiod for TW [10,11], semen output [18], and circulating LH and testosterone concentrations [6-9]. The present results confirmed previous observations [10,11] that prepubertal male turkeys maintained under constant long days are precocious semen producers (26-29 wk) In

Table 3

Correlation coefficients and probability of significant difference between plasma concentrations of LH and testosterone, testis weights (TW) and WSO* in male turkeys sacrificed at $60 \mathrm{wk}$ of age

\begin{tabular}{|c|c|c|c|c|c|c|c|c|}
\hline & \multicolumn{2}{|l|}{$\mathrm{LH}$} & \multicolumn{2}{|c|}{ Testosterone } & \multicolumn{2}{|l|}{ TW } & \multicolumn{2}{|c|}{$\mathrm{WSO}^{\mathrm{a}}$} \\
\hline & $r$ & Probability & $r$ & Probability & $r$ & Probability & $r$ & Probability \\
\hline $\mathrm{LH}$ & 1.00 & - & 0.37 & 0.03 & -0.18 & 0.30 & 0.21 & 0.27 \\
\hline Testosterone & & & 1.00 & - & 0.11 & 0.55 & 0.23 & 0.20 \\
\hline TW & & & & & 1.00 & - & 0.26 & 0.12 \\
\hline $\mathrm{WSO}^{2}$ & & & & & & & 1.00 & - \\
\hline
\end{tabular}

\footnotetext{
${ }^{a}$ Weekly sperm output (estimated from five semen collections/wk) performed at 57-58 wk.
} 
contrast, prepubertal male turkeys exposed to strictly short days (7L:17D) had normal adult BW by $34 \mathrm{wk}$, but testicular development was delayed until after $46 \mathrm{wk}$ of age. Similar observations were reported for guineafowl [20] and fowl [21] exposed to strict short days. We suggest that this cannot be attributed to juvenile photorefractoriness that is expressed in wild birds not having reached full body development [19]. Our study also confirmed previous observations that a short, reputedly non-stimulatory photoperiod may induce precocious sexual maturity (26-29 wk) in a minority (here about 30\%) of the experimental population [9]. Hypothetically, such turkeys possess the genetic capacity to reach a functionally reproductive state when subjected to a "normally" non-stimulatory environment.

In males subjected to increasing photoperiods, WSO increased about 6 wk after the onset of the increased photoperiod, whereas increases in plasma LH and testosterone were detectable only $2-3 \mathrm{wk}$ after the onset of stimulation ( $23 \mathrm{wk}$ ). Plasma $\mathrm{LH}$ and testosterone increased within $1 \mathrm{wk}$ in males exposed to a 14L:10D photoperiod. We inferred that immature male turkeys more rapidly express their photoperiod sensitivity after a sudden rather than a progressive light increase. However, plasma LH and testosterone concentrations both peaked higher (although later) under a progressively increasing rather than suddenly increased photoperiod.

We also observed that male turkeys under a moderately short photoperiod (10.5L:13.5D) achieved full testicular development as early as males under a long or increasing photoperiod. These results, reported for the first time in turkeys, raised the question of a possible threshold effect of photoperiod in this species. However, mean plasma LH and testosterone in males under a $10.5 \mathrm{~L}: 13.5 \mathrm{D}$ photoperiod were very similar to those observed under 7L:17D, but not to those observed under long or increasing day-lengths. Therefore, LH and testosterone concentrations in males subjected to a 10.5L:13.5D photoperiod following prolonged exposure (from 17 to $23 \mathrm{wk}$ ) to short days (7L:17D), did not respond to this transition as an increasing photoperiod but, rather as another prolonged period of short days.

So what is the exact nature of the signal for testes development in birds after stimulation by light? Indeed, an apparent paradox exists between the persistently low levels of circulating $\mathrm{LH}$ and $\mathrm{T}$ and the degree of development of the testes and the high rates of semen output observed in Group 2. Yang et al. [9] indicated that plasma LH (but not testosterone) concentrations followed a pattern similar to semen production, at least within the first $6-8$ wk following sexual maturity. This was observed in Groups 1, 3, and 4. However, in Groups 2 and 8, plasma LH and testosterone concentrations were comparable to those observed under a short photoperiod (7L:17D) although testis weights and semen output followed the same pattern observed under long or increasing photoperiods. We therefore hypothesized that a moderately short photoperiod such as $10.5 \mathrm{~L}: 13.5 \mathrm{D}$ may have induced sufficient release of GnRH to stimulate the gonadotropic action of LH or FSH, or both.

Despite the variability of TW and WSO between groups, all group means for TW and WSO at $60 \mathrm{wk}$ of age were similar within each experiment. The general tendency for a moderate decrease in TW and WSO at 60 wk in groups under constant long or increasing photoperiods was probably the consequence of negative feedback exerted by gonadal steroids on the hypothalamic-hypophysial axis. Using hypothalamic implants of testosterone in the quail, Follett [22] demonstrated the inhibitory effect of testosterone on LH secretion, a result later confirmed by Godden and Scanes [3] in the turkey and by Wilson [23] in the fowl. Male birds generally responded to a stimulatory photoperiod with an increase in the synthesis and release of LH and FSH that initiated and maintained development of the testes (quail [24,25]; turkey, 4). This was confirmed for $\mathrm{LH}$ in the present experiments, with the exception of testis development among males in Groups 2, 6, and 8. These precocious males were under a long constant or increasing photoperiod. Subsequently, the increase in plasma LH was much more gradual than that observed with short days (7L:17D). Observations of Groups 2, 6, and 8 also indicated that gonad development in turkeys, as in quail [26,27] and fowl [28] subjected to ahemeral light regimes, can be stimulated by an additional period of illumination $(1 \mathrm{~h}$ here) given during the photosensitive phase. In the present study, reproductive characteristics were considerably delayed in males under a variable photoperiod of 9.5L:14.5D (Group 7). Therefore, the onset of the photosensitive phase in male turkeys probably coincides with a period of the circadian rhythm starting more than $9.5 \mathrm{~h}$ and less than $10.5 \mathrm{~h}$ after the light/dark interface.

Weekly sperm output increased in males raised under a 7L:17D photoperiod, and to a lesser extent, in males raised under a variable 9.5L:14.5D, long after WSO had reached its maximum in the other groups. This confirmed previous reports that a strictly short photoperiod per se $(7 \mathrm{~L}$ or $8 \mathrm{~L} /$ day) has a non-stimulatory effect on reproductive traits (fowl: [29,30]; turkey: [10,11]; guinea-fowl: [20]). By contrast, in male turkeys a moderate or even shorter photoperiod such as 
10.5L:13.5D from 23 wk of age appeared to be stimulatory by 30-34 wk of age. The absence of difference in WSO between males raised under a 10.5L:13.5D or $14 \mathrm{~L}: 10 \mathrm{D}$ photoperiod confirmed that under these photoperiods, male turkeys fully develop their reproductive potential at early stages of reproductive life. In addition, our results regarding the effects of long $(14 \mathrm{~L})$ and short $(7 \mathrm{~L})$ photoperiods on the percentage of semen producers agreed with Dobrescu [31] who observed that $100 \%$ of the turkeys aged 29 or 50 wk produced semen under a $14 \mathrm{~L}: 10 \mathrm{D}$ or $8 \mathrm{~L}: 16 \mathrm{D}$ photoperiod, respectively.

That WSO decreases progressively with age in males under a long or increasing photoperiod has probably the same origin as the seasonal decline in semen output in male turkeys subjected to natural variations in photoperiod [32-35]. Interestingly, while independent of photoperiod, sperm viability declined $(P<0.05)$ with age. This observation agreed with that of Wall and Jones [36] who reported a decline in semen quality after 3 mo of production. With the exception of $\mathrm{LH}$ and testosterone at 59 wk of age, no significant correlation was observed in Experiment 1 between the various parameters analyzed. This in part confirmed previous reports (fowl: [37]; turkey: [5,38]) that although ultimately interdependent, the interrelationships between plasma LH or testosterone and semen output were not linked in a direct manner.

In conclusion, in the present study, turkeys were brought into semen production by a constant long (14L:10D) or an increasing photoperiod (from 7L:17D to 14L:10D). In addition, a moderately short or a variable light period of more than $9.5 \mathrm{~h}$ but less than $10.5 \mathrm{~h} /$ day also lead to semen production. We tentatively recommend that breeder turkey males can be brought into and maintained in semen production under such photoperiods. Our results also indicated that plasma $\mathrm{LH}$ and testosterone in male turkeys subjected to moderately short days (10.5L:13.5D) were closer to those observed under short (7L:17D) rather than under long or increasing days. We inferred that the sensitization of the gonadotropic axis by photoperiod was sufficient to induce testicle development without major changes in plasma concentrations of LH or testosterone. From a practical standpoint, therefore, plasma LH or testosterone might be considered non-pertinent parameters to predict testis weight or sperm output in male breeder turkeys.

\section{Acknowledgements}

This research was supported by a cooperative research partnership with CIDEF (Comité Interpro- fessionnel de la Dinde en France). We wish to thank Dr. D. Guémené and Dr. J. Williams for useful advice regarding hormone assays. We also thank M. Mills and S. Nevoit for their technical assistance and Dr. C. Gossage for helpful discussions regarding the manuscript.

\section{References}

[1] Howarth B. Physiology of reproduction: the male. In: Hunton P, editor. Poultry production (production-system approach). Amsterdam: Elsevier Press; 1995. p. 243-70 [Chapter 9].

[2] Sharp PJ. A comparison of variations in plasma luteinizing hormone concentrations in male and female domestic chickens (Gallus domesticus) from hatch to sexual maturity. J Endocrinol 1975;67:211-23.

[3] Godden PM, Scanes CG. Gonadotrophin concentrations during growth and maturation in domestic turkeys. Br Poult Sci 1977;18:675-85.

[4] Godden PM, Scanes CG. Effect of photoperiod on gonadotrophin concentrations in domestic turkeys. Br Poult Sci 1977; 18:687-94.

[5] Cecil HC, Bakst MR. Serum testosterone concentration during two breeding cycles of turkeys with low and high ejaculate volume. Domest Anim Endocrinol 1986;3:27-32.

[6] Bacon WL, Proudman JA, Foster DN, Renner PA. Pattern of secretion of luteinizing hormone and testosterone in the sexually mature male turkey. Gen Comp Endocrinol 1991;84:447-60.

[7] Bacon WL, Kurginski-Noonan BA, Yang J. Effects of environmental lighting on early semen production and correlated hormonal responses in turkeys. Poult Sci 2000;78:1669-78.

[8] Bacon WL, Long DW, Kurima K, Chapman DP. Coordinate pattern of secretion of Luteinizing hormone and testosterone in mature male turkeys under continuous and intermittent photoschedules. Poult Sci 1994;73:864-70.

[9] Yang J, Long DW, Inpanbutr N, Bacon WL. Effects of photoperiod and age on secretory patterns of luteinizing hormone and testosterone and semen production in male domestic turkeys. Biol Reprod 1998;59:1171-9.

[10] Krueger KK, Owen JA, Krueger CE, Ferguson TM. Effect of feed or light restriction during the growing and breeding cycles on the reproductive performance of broad breasted white turkey males. Poult Sci 1977;56:1566-74.

[11] Noirault J, Brillard JP, Bakst MR. Spermatogenesis in the turkey (Meleagris gallopavo): quantitative approach in mature and adult males subjected to various photoperiods. Theriogenology, in press.

[12] George B. Research needed to sustain fertility and hatchability. In: Fifth international symposium on turkey reproduction; 1973.p. 209-43.

[13] Burrows WH, Quinn JP. The collection of spermatozoa from the domestic fowl and turkey. Poult Sci 1937;16:19-24.

[14] Noirault J, Brillard JP. Effects of frequency of semen collection on quantitative and qualitative characteristics of semen in turkey breeder males. Poult Sci 1999;78:1034-9.

[15] Donoghue AM, Garner DL, Donoghue DJ, Johnson LA. Viability assessment of turkey sperm using fluorescent staining and flow cytometry. Poult Sci 1995;74:1191-200.

[16] Sharp PJ, Dunn IC, Talbot RT. Sex differences in the LH responses to chicken LHRH-I and -II in the domestic fowl. J Endocrinol 1987;115:323-31. 
[17] Guémené D, Williams JB. In-vitro and in-vivo responses to chicken LHRH-I and chicken LHRH-II in male turkeys (Meleagris gallopavo). J Endocrinol 1992;132:387-93.

[18] Driot FJM, Garnier DH, Terqui M. Development and validation of a "direct" radioimmunoassay for plasma testosterone in the fowl (Gallus domesticus). Gen Comp Endocrinol 1978;36: 244-9.

[19] Etches RJ, Uribe H, Bagley LG. Precocious semen production in turkeys. Poult Sci 1993;72:193-201.

[20] Brillard JP, de Reviers M. Testis development and daily sperm output in guinea-fowl raised under constant daily photoperiods. Reprod Nutr Dév 1981;21:1105-12.

[21] de Reviers M. Le développement testiculaire chez le coq, III Influence de la durée quotidienne d'éclairement sous photopériodes constantes. Annales de Biologie Animale de Biochimie et de Biophysique 1974;14:591-600.

[22] Follett BK. The neuroendocrine regulation of gonadotrophin secretion in avian reproduction. In: Farmer DS, editor. Breeding biology of birds. Washington DC: National Academy of Sciences Press; 1973. p. 209-43.

[23] Wilson SC. Secretion in the cockerel and the effects of castration and testosterone injections. Gen Comp Endocrinol 1978;35:48190.

[24] Nicholls TJ, Scanes CG, Follett BK. Plasma and pituitary LH in Japanese quail during photoperiodically induced gonad growth and regression. Gen Comp Endocrinol 1973;21:84-98.

[25] Follett BK, Maung SL. Rate of testicular maturation, in relation to gonadotrophin and testosterone levels, in quail exposed to various artificial daylengths and to natural daylengths. J Endocrinol 1978;78:267-80.

[26] Follett BK, Sharp PJ. Circadian rhythmicity in photoperiodically induced gonadotrophin release and gonadal growth in the quail. Nature 1969;223(5209):968-71.
[27] Follett BK, Milette JJ. Photoperiodism in quail: testicular growth and maintenance under skeleton photoperiods. J Endocrinol 1982;93:83-90.

[28] de Reviers M. Photopériodisme, développement testiculaire et production de spermatozoïdes chez les oiseaux domestiques. INRA Productions animales 1996;9:35-44.

[29] Parker JE, McCluskey WH. The effect of the length of daily light periods on the volume and fertilizing capacity of semen from male chickens. Poult Sci 1964;43:1401-5.

[30] Parker JE, McCluskey WH. The effect of length of daily light periods on sexual development and subsequent fertilizing capacity of male chickens. Poult Sci 1965;44:23-7.

[31] Dobrescu O. Photoperiod, diet and method of feeding on reproduction. Poult Sci 1986;65:559-64.

[32] Parker JE. The influence of season on reproduction in turkeys. Poult Sci 1947;26:118-21.

[33] Carson JD, Lorenz FW, Asmundson VS. Semen production in the turkey male. 1. Seasonal variation. Poult Sci 1955;34:336-43.

[34] Carson JD, Lorenz FW, Asmundson V. Semen production in the turkey male. 3. Quantities produced. Poult Sci 1955;34:348-55.

[35] Dalrymple JR, McPherson JW, Friars GW. The effect of season on testicular weight and spermatogenesis in turkeys. Can J Comp Med 1968;32:437-9.

[36] Wall KA, Jones JE. Effect of restricted daylength during the growing period on semen quality and fertility of turkey toms. Poult Sci 1976;55:425-30.

[37] Williams J, de Reviers M. Variations in the plasma levels of luteinizing hormone and androstenedione and their relationship with the adult daily sperm output in cockerels raised under different photoschedules. Reprod Nutr Dév 1981;21:1125-35.

[38] Cecil HC, Bakst MR. Testosterone concentrations in blood and seminal plasma of turkeys classified as high or low semen producers. Poult Sci 1988;67:1461-4. 